\title{
Ethical recommendations for ocean observation
}

\author{
Michèle Barbier ${ }^{1}$, Anja Reitz ${ }^{2}$, Katsiaryna Pabortsava ${ }^{3}$, Anne-Cathrin Wölfl' ${ }^{2}$, Tobias Hahn ${ }^{2}$, and Fred Whoriskey \\ ${ }^{1}$ Institute for Science and Ethics, Nice, France \\ ${ }^{2}$ GEOMAR Helmholtz Centre for Ocean Research Kiel, Germany \\ ${ }^{3}$ National Oceanography Centre Southampton, UK \\ ${ }^{4}$ Ocean Tracking Network, University of Dalhaousie, Halifax, Canada
}

Correspondence: Michèle Barbier (mbarbier@ sciencethics.org)

Received: 3 July 2018 - Revised: 12 September 2018 - Accepted: 22 October 2018 - Published: 22 November 2018

\begin{abstract}
The United Nations proclaimed a decade of marine science for sustainable development (2021-2030) to develop a common framework that will ensure that ocean science can fully support countries in achieving the goal of sustainable development. Marine scientific understanding is fundamental to managing human activities that affect this environment, and ocean observations have a particularly important role in enhancing the knowledge base of our oceans. With this important task, scientists have the responsibility to act in an ethical way and apply all the fundamental principles described in the Cape Town statement: (a) ethical values, (b) social values and (c) cultural values (Peppoloni and Di Capua, 2017).

This article is a fist attempt to highlight the core values applicable to ocean observation, which can then be improved and adopted as part of geoethics and the stewardship of the Earth system. It opens up avenues for reflection on geoethical implications in the field of ocean observation and suggests nine key principles that marine scientists could follow in their innovative research regarding open access to data, effectiveness, compliance with laws, environmental respect and nature conservation, reciprocal relation and cultural respect, equity and fairness, knowledge transfer, governance adapted to socio-ecological systems, and the use of animals in research.
\end{abstract}

\section{Introduction}

The oceans are part of the complex ocean-atmosphere cycle that regulates the global climate and are vulnerable to natural and man-made hazards. However, the ocean remains one of the least-known regions in the world. Scientific understanding is fundamental to managing human activities that affect this environment, and ocean observations heavily enhance the knowledge base of our oceans. Understanding this ecosystem is essential to predicting extreme oceanographic and climatic events as well as geohazards (storms, hurricanes, sea level rise and coastal erosion), pollution, oil spills, invasive species, acidification and deoxygenation. We have entered a new geological era, the Anthropocene, as a result of human pressures on the Earth system (UN, 2016; Nakicenovic et al., 2016). Therefore, knowledge of the oceans and of the Earth system as a whole is an essential basis for appropriate sustainability management. "The Anthropocene is changing our relationship with the planet and we must determine how to assume this responsibility" (Nobel Laureate Elinor Ostrom, 1933-2012; Planet Under Pressure, 2012). In Anthropocene governance, decisions are based on scientific evidence (Nakicenovic et al., 2016). Humanity must be the steward of the planet's natural resources and scientists must participate not only in the production of knowledge, but also in public discourse, decision-making, education and governance to reduce anthropogenic damage to the environment (Rozzi et al., 2015; Bohle and Erle, 2017; Peppoloni et al., 2015; Peppoloni and Di Capua, 2015, 2016; Bobrowsky et al., 2017). Scientists must be concerned with societies and environments and be aware of their role in the Earth system as well as their relationships with colleagues (Bobrowsky et al., 2017; Bohle and Erle, 2017). 
Responsibility is one of the values that the human community accepts as universally representative of individual and social good in terms of honesty, justice, and respect for life and the environment. Responsibility is also a value shared by marine scientists and geoscientists. Responsibility for marine research activities is reflected in philosophy (Jonas, 1979), legislation (UNCLOS, 1982, Agenda 21, 1992) and geoethics (Peppoloni and Di Capua, 2015, 2016; Peppoloni et al., 2015; Wyss and Peppoloni, 2015).

In the 1970s, the German philosopher Hans Jonas (19031993) wrote the following: "Modern technology has introduced actions of such magnitude, objects and unprecedented consequences that the framework of ancient ethics can no longer contain them". Jonas was concerned about the enormous power that comes from the technical sciences (such as genetic engineering, environmental technology, satellites) and understood the need to involve a new form of responsibility (Jonas, 1979). The "imperative of responsibility" for future humanity has become a principle and, as such, it is the precursor to the precautionary principle. Scientists must ensure that the effects of their actions do not destroy the autonomy, dignity, integrity and vulnerability of future humanity (Berdinesen, 2017). This new conception of the ethics of the future goes far beyond philosophical theory in influencing national and international legal or political systems to integrate the concepts of "common heritage of humanity", "sustainable development" and "future generations" (Gaillard, 2015; Mantatov and Mantatova, 2015).

Ambassador Arvid Pardo of Malta proposed to the United Nations in 1967 that the seas and oceans beyond national jurisdiction should be considered as the common heritage of humanity. It has also developed an ethical concept for a new world order based on new forms of cooperation, economic theory and philosophy: the oceans and their resources are a common good open to the international community, and their use should be subject to international administration and management for the common good of all humanity. States should commit themselves to managing and protecting existing resources within their national jurisdiction, but as a global interest and not only for national interests (Prue, 2011); it is the ethical core of the common heritage of humanity: the responsibility of human beings to protect and maintain the environment as a whole, of which we are a part for present and future generations.

The International Association for the Promotion of Geoethics (IAPG) ${ }^{1}$ was recently launched to create a multidisciplinary scientific platform to broaden debate and raise awareness of ethical issues applied to geoscience, thus providing a landscape for the development of geoethics. To help address ethical issues, the values of geoethics have been defined to adopt appropriate behaviours and practices by choosing the best solution to a problem that must consider differ-

\footnotetext{
${ }^{1}$ IAPG - http://www.geoethics.org/ (last access: 9 November 2018).
}

ent dimensions aligned with shared values (Peppoloni and Di Capua, 2015, 2017; Peppoloni et al., 2017). Geoethics has been defined as "research and reflection on the values that underlie appropriate behaviours and practices, wherever human activities interact with the Earth system. Geoethics addresses the ethical, social and cultural implications of knowledge, education, research, practice and communication in geosciences, as well as the social role and responsibility of geoscientists in the conduct of their activities" (Bobrowsky et al., 2017; Peppoloni and Di Capua, 2012). The Cape Town statement on geoethics sets out the fundamental principles of geoethics such as the honesty, integrity, transparency and reliability of geoscience and highlights, in particular, three aspects that are important for the marine environment: (1) respect for natural processes and phenomena, to the extent possible, when planning and implementing environmental interventions; (2) ensuring the sustainability of economic and social activities to ensure the supply of energy and other natural resources for future generations; and (3) promoting geoeducation and awareness for all to promote sustainable economic development, prevent and mitigate geological risks, environmental protection, and improve the resilience and well-being of societies (Violante et al., 2017).

The United Nations has proclaimed a decade of marine sciences for sustainable development (2021-2030) to develop a common framework that will enable the ocean sciences to fully assist countries in achieving the goal of sustainable development. One of the objectives is to achieve the integration of observations and data sharing, including the use of satellites, fixed and mobile observation platforms, and shipboard observation platforms (IOC-UNESCO, 2017). Ocean observing systems will become a major asset in this task and it is incumbent on the marine scientific community to adopt an ethical approach in its research. To promote geoethics among the marine scientific community, this article lists some of the most fundamental values of ocean observation in order to sensitize scientists and managers of largescale scientific projects to integrate an ethical approach into their future project work plans.

We open up avenues for reflection on geoethical implications in the field of ocean observation and suggest nine key principles that marine scientists could follow in their innovative research, inspired by the CIESM Charter and based on the AtlantOS H2020 project used as a case study.

We define ethics in ocean observing systems as reasoned reflection and actions based on research activities and technological advances to develop ocean knowledge that takes into account external factors such as the social, legal, political, economic, environmental and cultural dimensions in order to provide advice for commendable and responsible behaviour that will support sustainability, the stability of our oceans and the resilience of the Earth system. 


\section{EU Horizon 2020 project AtlantOS as a key study for an ethical approach to ocean science}

The AtlantOS project (H2020 project 2015-2019) aims to enhance and optimize the integrated Atlantic Ocean observing systems. One of the objectives of the AtlantOS network is to strengthen the cooperation and exchange of knowledge across countries, both in Europe and in the states bordering the entire Atlantic Ocean, to integrate all current research activities in ocean observing and to provide information and products necessary to cope with global challenges such as climate change, increased pressures on natural resources and global-scale hazards. The AtlantOS vision is to improve and innovate Atlantic observation to obtain an international, more sustainable, more efficient, more integrated, and fit-for-purpose system. By this means, the initiative aims for a long-lasting and sustainable contribution to realizing societal, economic and scientific benefits arising from this integrated approach that will extend beyond the AtlantOS project's lifetime. The revised ocean observing system seeks to provide new information products in several societal benefit areas (i.e. climate, risks, ecosystems, health and fresh water) including safety for offshore activities and coastal communities. The AtlantOS project pools the effort of 62 partners (research institutes, universities, marine service providers, multi-institutional organizations and the private sector) from 18 countries, including Europe, Canada, the US, Brazil and South Africa. It has a budget of almost EUR 21 million for 4 years (2015-2019) and is coordinated by the GEOMAR Helmholtz Centre for Ocean Research Kiel, Germany (Martin Visbeck).

From its inception, the AtlantOS project already recognized the concept of responsible research and innovation (RRI) to address important societal challenges. It has addressed this by adopting principles of responsible science and innovation and directing research and innovation efforts towards valued societal objectives. RRI means that societal actors work together throughout the research and innovation process to better align the process and its results with society's values, needs and expectations (European Commission, 2014). RRI is an approach that anticipates and assesses potential societal implications and expectations for research and innovation, with the aim of fostering the design of inclusive and sustainable research and innovation that considers different dimensions such as public engagement and awareness, open science, science education, ethics, governance and gender equality (e.g. H2020 projects MARINA and Baltic Gender). Within AtlantOS, almost every work package (WP) is coordinated by both a man and a woman, and a strong communication strategy is deployed; one WP is dedicated to the definition of societal requirements, and one WP is dedicated to data management with strong encouragement to provide free and open access to data. All dissemination activities of the project are open and freely available.

\section{Ethics - key recommendations}

In ocean sciences, ethical guidelines have been designed at CIESM $^{2}$ (Mediterranean Science Commission, Barbier and Briand, 2014) in the context of access and use of marine genetic resources (Giuliano and Barbier, 2011, 2014). CIESM is an intergovernmental organization supported by 23 member governments to promote international research in the Mediterranean and Black Sea. The commission covers a broad spectrum of marine disciplines, relying on a pool of vast human resources. On this basis, CIESM produces authoritative, impartial reports on the status and trends of Mediterranean marine systems, together with sharp recommendations on priorities for actions, research and development on a large range of sensitive issues concerning the whole Mediterranean Basin. These guidelines, embedded into the CIESM Charter on Access and Benefit Sharing (ABS) arising from the utilization of marine genetic resources, were designed in 2014 to reinforce the Nagoya Protocol $^{3}$ in the Mediterranean. The Nagoya Protocol on Access to Genetic Resources and the Fair and Equitable Sharing of Benefits Arising from their Utilization (ABS) to the Convention on Biological Diversity is an international agreement which aims at sharing the benefits arising from the utilization of genetic resources in a fair and equitable way. The Nagoya Protocol, which entered into force in 2014, is a complement to the Convention on Biological Diversity - the CBD adopted in 1992 at the United Nations Conference on Environment and Sustainable Development in Rio - for which economic and social development related to environmental protection and sustainable development was at the heart of the debate. The CBD was adopted to protect biodiversity, highlighting the need for the sustainable use of biodiversity and maintaining the integrity of ecosystem functioning to ensure the viability of biodiversity (UNCLOS, 1982; De Paiva Toledo, 2016). The CBD was reinforced by Action Agenda 21, which is an action plan for the 21st century adopted by 173 heads of state at the Earth Summit in Rio de Janeiro in June 1992. Principle 15 is a precautionary principle aiming to anticipate any negative impact and sustainably exploit resources in the high seas.

The CIESM Charter on Access and Benefit Sharing arising from the utilization of marine genetic resources has been conceived to stimulate scientific research and development and provides ethical guidelines for providers, enquirers and end users (http://www.ciesm.org/marine/charter/index.php, last access: 9 November 2018). The charter emphasizes essential core values, such as fair and equitable sharing of benefits, transparency and reciprocal relations, and fostering the sharing of scientific knowledge with concerted handing of data, traceability, nature conservation and environmental respect. It has been developed on the basis of extensive consul-

\footnotetext{
${ }^{2}$ http://www.ciesm.org (last access: 9 November 2018).

${ }^{3}$ https://www.cbd.int/abs (last access: 9 November 2018).
} 
tation with scientists and legal experts to maintain and protect access to knowledge for everyone to prevent abuses of ocean global commons. The CIESM Charter goes beyond biological approaches and extends beyond the strict perimeter of the Mediterranean-Black Sea regions. Its concept is applicable to large scientific initiatives such as oceanographic campaigns in the global oceans.

The ethical key points related to ocean observing and the subsequent recommendations below are inspired or adapted from the CIESM Charter and recall geoethics fundamental principles (Peppoloni and Di Capua, 2016). They provide the foundation for the nine recommendations below, which are based on philosophical, scientific, environmental, societal or legal dimensions. These recommendations are illustrated by concrete examples.

\subsection{Open access to data}

Technoscience has provided the marine scientific community with new opportunities to improve the understanding of ocean systems. For example, satellites are now used to transmit oceanographic data in real time or near-real time, providing information on changes happening in the ocean in time and space. Although these data have been obtained from many studies in different seas, their use is not yet optimal due to restricted availability. The benefit of linking the data across different sectors readily and freely can therefore be lost. Moreover, access to data can be restricted by some governments for historical reasons or by some companies (a) due to potential security reasons or (b) because they earn money with the data they produce (Bernal and Simcock, 2016; UN data revolution report, 2014). The United Nations recently called for action from scientific communities, industries and policymakers to support aspirations for sustainable development and avert risks, stop and reverse growing inequalities in access to data and information, and ensure that the promise of the data revolution is realized for all (UN data revolution report, 2014). Data sharing and access are fundamental for improving the ways we observe the oceans, especially because it prompts collaborations between different scientific fields (multidisciplinary) and nations (Muller-Karger et al., 2018). Free data access has been advocated by many international programmes and organizations. For instance, many marine initiatives in Europe follow the practices outlined in the UNESCO Report on Observations and Samples Collected by Oceanographic Programmes (ROSCOP, late 1960s) and CSRs (Cruise Summary Reports (since 1960). The GOOS 2030 strategy specifically emphasizes this point to ensure that ocean observation data and information are searchable, accessible, interoperable and reusable with appropriate quality (Toste Tonhua, personal communication, 2018). The European Commission also strongly encourages open access to data to improve the quality of results, encourage collaboration, increase efficiency of data collection, avoid duplication of effort, and foster innovation and faster product delivery to the market to improve the overall transparency of the scientific process. Industry is also becoming more open in disclosing their data to the scientific community (Sylvie Pouliquen, personal communication, 2018)

Along with the rapid development of open-access data platforms, the scientific community is becoming increasingly engaged in sharing data and knowledge. One of the AtlantOS objectives is to "showcase the power of integrated transAtlantic observing to provide information necessary to cope with global challenges such as climate change, increased pressure on natural resources and global-scale hazards to the benefit of society"; this meets the principle of open access to data.

As an example, data on the Argo Data System, through which all data from the Argo international programme ${ }^{4}$ are stored, are relayed and made publicly and freely available within hours after collection. Argo is the international array of $\sim 3900$ free-drifting profiling floats that provides measurements temperature and salinity profiles from the surface down to $2000 \mathrm{~m}$ below sea level every 10 days, with years of data on the temperature and salinity of the global ocean. Measuring temperature and salinity with Argo floats provides the physical data necessary for a wider scientific community than physical oceanographers. In Europe, Euro-Argo ${ }^{5}$ is managed by IFREMER, who put a lot of effort into coordinating the data flux. The Prediction and Research Moored Array in the Tropical Atlantic Network, PIRATA ${ }^{6}$, puts at the disposal of the scientific community a unique $>20$-year time series of ocean monitoring data from the tropical Atlantic, which is indispensable for global climate change monitoring. These data are crucial for global climate change monitoring. PIRATA includes France (IRD, Météo France, IFREMER and CNRS/INSU), Brazil (DHN and INPE) and the USA (NOAA/PMEL). The scientific communities involved share data based on voluntary participation. These include the IHO-DCDB (International Hydrographic Organisation) collecting bathymetric data and the recently launched Seabed 2030 initiative ${ }^{7}$.

All these programmes and projects are united by the same objective, which is collecting high-quality data. Based on the UN definition, data are of high quality when they are accurate, comparable, unbiased, relevant, timely and accessible. Data interoperability and standardization are crucial because they allow data from different sources or time periods to be combined and are essential criteria for defining the high quality of data (Muller-Karger et al., 2018; Bernal and Simcock, 2016; UN report on data revolution, 2014). As an example, the ocean modelling community needs to integrate physical,

\footnotetext{
${ }^{4}$ http://www.argo.org (last access: 9 November 2018).

${ }^{5}$ Euro-ERIC is coordinated by Ifremer, France (http://www. euro-argo.eu/, last access: 9 November 2018).

${ }^{6}$ http://www.brest.ird.fr/pirata/index.php (last access: 9 November 2018).

${ }^{7}$ https://seabed2030.gebco.net/ (last access: 9 November 2018).
} 
bathymetric, chemical, biogeochemical and biological data to verify and build confidence in their simulations. Moreover, by combining biological and geological data, we can define habitat maps for valued species, delineate the boundaries of marine protected areas (MPAs), inform their monitoring plans and define ecosystem status.

These data, which are interoperable, standardized and of high quality, can be considered as common data that must be managed in a concerted manner. The scientific community should ensure that contributors share responsibilities through data preservation, dissemination and management, which must be clear and transparent. Data must be visible and managed through established data management facilities.

To engage in a trustful relationship, keeping track of the following is essential: data and information, metadata, other environmental variables, any persons involved (private or work-related contact) in collecting the data, the sampling dates and locations where relevant, and the state of the data in the quality control process (e.g. final data, (un)calibrated, raw, etc.). The platforms gathering data must make the data openly available and provide details on data quality assurance-quality control (QA-QC) and processing procedures, including the methods used, reference persons, third parties involved in any procedures and where the results are hosted.

Finally, this principle does not contravene principles 4 (compliance with laws) and 5 (reciprocal relations; see below). The decision taken by a country on whether or not to provide access to data obtained in their national waters needs to be respected. Data obtained in the sovereign waters of a nation require agreements with the state for the information to become public.

The main recommendations for promoting open access to data are as follows.

- Make the results of research activities visible and free, and share access to data to improve our knowledge of the oceans.

- Optimize the integration of data into a global ocean observing system using criteria of interoperability, data quality, standardization or best practices when available.

- Respect cultural and scientific diversity in data management.

- Define and harmonize vocabulary while collaborating across sectors or disciplines.

\subsection{Effectiveness}

For ocean observations to be sustained, the collection of data must be efficient. Efficient ocean observing networks provide high-quality, robust and timely products, services and data to the scientific community, society, stakeholders and policymakers.

These observations are also multi-purpose, resilient and yet can be adapted to ensure relevant improvements, innovation and growth. As an example, large areas in the Atlantic Ocean have been mapped by various industries, but as these data are not publicly available, scientists map the same areas repeatedly. This is costly. Collaboration should be encouraged to increase the efficiency of ocean observing ${ }^{8}$.

Sharing existing infrastructure and facilities for ocean observing (e.g. fixed-point observatories, research vessels, autonomous platforms such as gliders, floats, etc.) prevents duplication of effort, minimizes investments, and ultimately reduces service and maintenance costs. This also allows for the future enhancement of observing capacity through the implementation and integration of new technologies and new sensors, the optimization of existing practices (best practices), and the development of new ones. It drives innovation for the understanding of the oceanic environment and processes. To provide a solid base of information on the main in situ elements of the global ocean observing system (current ocean parameters measured) and thus help reduce duplication in sampling, the Joint WMO-IOC Technical Commission for Oceanography and Marine Meteorology (JCOMM) provides a comprehensive platform and monitoring tool on what is measured, where and how ${ }^{9}$. The JCOMM in situ Observations Programme Support Centre (JCOMMOPS) is based on the existing DBCP, OceanSITEs, SOT, GO-SHIP and Argo coordination mechanisms. The centre provides essential data and tools, as well as a centralized information and technical support facility, required for coordinating and integrating many of the existing operational ocean observing networks under JCOMM. EMODnet ${ }^{10}$ follows a similar approach but for European contributions with a focus on users and data platforms.

To address the needs of society and researchers, and to deliver the expected benefits from sustained ocean monitoring, AtlantOS utilizes and builds on the capabilities of existing ocean observing platforms including infrastructure, resources, data management protocols, and knowledge transfer and exchange. Collaboration and partnership between international research institutes and the industrial and private sectors have been fostered to ensure mutual short- and long-term support and benefit.

In AtlantOS, most working groups focus on improving observation efficiency by strengthening observation networks, establishing interfaces between open, regional and coastal networks, cross-cutting technologies and observing system

\footnotetext{
${ }^{8}$ https://www.marinetechnologynews.com/news/ ocean-infinity-donates-seabed-561884 (last access: 9 November 2018) Ocean Infinity donates data to seabed mapping project.

${ }^{9}$ http://www.jcommops.org (last access: 9 November 2018).

${ }^{10}$ EMODnet is operated by EuroGOOS (http://www.emodnet. eu/, last access: 9 November 2018).
} 
practices in the most cost-effective way. They also focus on harmonizing data flow and integration so that essential ocean variables (EOVs) are measured and can provide the best information to society. These EOVs are defined within the marine scientific community to meet the requirements of stakeholders, users and customers. Management and innovation procedures are being developed to improve and integrate international observation networks and create a sustainable European and transatlantic infrastructure.

In many cases, such collaborations and sharing of observing infrastructure have already been conducted in practice: the Fixed-point Open Ocean Observatory network (FixO3) ${ }^{11}$ has put a large effort into integrating European open ocean fixed-point observatories and improving access to these key installations for a broader community. FixO3 was coordinated by the National Oceanography Centre (UK) with 29 partners from academia, research institutions and private partners to improve integration and harmonize the existing technological, procedural and infrastructure processes. Members of the FixO3 consortia were able to access the data service and products of the observatory infrastructure in the Atlantic Ocean in a coordinated manner and free of charge. The research project enhanced and innovated the capability for multidisciplinary in situ ocean observations, data output, and data access and sharing. Furthermore, it fostered strong links with wider communities across academia, industry, policy and the general public through outreach, knowledge exchange and training activities. PIRATA is another example of a platform offering additional measurements through the integration of supplementary sensors on the PIRATA buoys for communities beyond those that were originally intended to be served by the infrastructure (e.g., acoustic receivers to track acoustically tagged animals for global animal trackers) but also through opportunities offered for additional studies and/or monitoring during yearly dedicated cruises, thereby optimizing vessel time use. Activities also include improvement, expansion, integration and innovation in shipbased observations undertaken by existing observing networks. These include the GO-SHIP network, the Voluntary Observing Ship (VOS) scheme, the Ship of Opportunity Program (SOOP) and FerryBox networks, which use voluntary observing ships and oceanographic research vessels to obtain oceanographic data. In Germany, every ship (three at present) going to international waters for scientific purposes is obliged, on transit, to record bathymetric data for the geological community. At the EU level, Eurofleets ${ }^{12}$ is a consortium of 31 partners from 20 countries supported by the EC to provide access to as well as coordinate and develop services for research vessels and equipment.

Effectiveness can also be based on the commitment of civil society. AtlantOS also collaborated with Volvo Ocean Race

\footnotetext{
${ }^{11} \mathrm{http}: / /$ www.fixo3.eu (last access: 9 November 2018).

${ }^{12} \mathrm{http}: / / \mathrm{www}$. eurofleets.eu/np4/home.html (last access: 9 November 2018).
}

(VOR) teams to collect oceanographic data for research, monitoring and operational services (e. g. weather forecasts). These activities were supported by project and transatlantic cooperation partners such as the National Oceanic and Atmospheric Administration (NOAA), JCOMMOPS (UNESCOIOC), GEOMAR and SubCtech.

The main recommendations to improve the effectiveness of the ocean observing system are as follows.

- Provide access to observation platforms and infrastructure to accommodate new measurements and integrate new sensors or devices.

- Adopt a multidisciplinary, flexible approach and adapt your platforms and measures to these new disciplines if this does not hinder major changes in the measures already carried out (e.g. biological measurements).

- Define best practices to help the ocean observing community adopt methodologies based on your expertise.

- Improve the visibility of the platforms, infrastructure and networks to the ocean observing community.

- Be open-minded to discussion and welcome new uses of the platforms.

\subsection{Environmental respect and nature conservation}

Before legislation and regulations were implemented, the ethical criteria for millennium were centred on the interest of humans and their community. American ecologist and philosopher Aldo Leopold (1887-1948) broadened our perspectives and, for many, transformed value systems by extending the concept of ethics to land and enlarging the boundaries of the human community to include soils, waters, plants and animals (Leopold, 1949). This concept has since been broadly supported and extended (for an overview, see Morand and Lajaunie, 2018). Environmental ethics are concerned with the moral relations that shape the linkage between humans and the natural word (Miller and Kirk, 1992). And because we have entered the Anthropocene "humanity must be the steward of the planet natural resources, ecosystems, biomes" and act accordingly (Nakicenovic et al., 2016)

The legal basis for the protection and preservation of the marine environment is provided by UNCLOS in harmony with the 1972 Stockholm Agreements. Article 192 (UNCLOS) refers to the obligation of states to protect the marine environment. The preamble states that we must be "conscious that the problems of ocean space are closely interrelated and need to be considered as a whole...", which implies a global approach within and beyond national jurisdiction. Environmental respect begins with controlling and continues up to the point of stopping pollution. Regional conventions and guidelines play an important role in environmental protection (Boyes and Elliott, 2014). For the northeast Atlantic region, the OSPAR Convention (1992) is the legal instrument to protect the marine environment; it obliges 
all contracting parties to take all possible steps to prevent and eliminate pollution and to take the necessary measures to protect this maritime area against the adverse effects of human activities (Article 1, OSPAR Convention).

Any observation and monitoring of the marine environment may disrupt the ecosystem. Environmental respect and nature conservation are key principles that need to be embraced by the research community. Scientists involved in ocean observing should, in particular, assess the environmental impact of their research in terms of noise pollution (e.g. single-beam and multibeam sonar systems, seismic testing), the fate of devices used as they approach their end of lifetime, long oceanographic campaigns employing single-use (disposable) sensors and waste management in general. The Intergovernmental Oceanographic Commission of UNESCO (IOC-UNESCO $)^{13}$ plays an important role in safeguarding the oceans from the impact of ship operators and marine scientific operations. Efforts have been made in this sense with a code of conduct for marine scientific research vessels which was approved by the International Ship Operator Community in China, (2007) ${ }^{14}$ highlighting the responsibility of scientists collecting scientific information to minimize their environmental impact.

The equipment deployed by researchers to monitor the ocean has minimal impacts (Bernal and Simcock, 2016) on the marine ecosystem compared to, for example, commercial shipping, drilling, operating offshore oil platforms, leisure vessels and dumping space instruments. This, however, does not absolve the research community from reducing their environmental impacts and showing leadership in reducing ocean pollution. Scientists within the framework of AtlantOS have identified several recommendations for reducing pollution from research activities (Barbier et al., 2016). Examples of prevention and control measures are the following:

i. encouraging float manufacturers to make their equipment more environmentally friendly by revisiting floats design (use of sustainable materials);

ii. conducting research and development on new battery technology posing less risk of impacts, developing better recovery-at-sea strategies for deployed equipment, especially equipment that unintentionally breaks free of its moorings;

iii. appropriate recycling or disposing of equipment that has reached its end of lifetime;

iv. developing a policy for recycling equipment;

v. collaborating with complementary networks (DBCP) to minimize the equipment deployed by maximizing the use of existing floats and/or drifters; and

\footnotetext{
${ }^{13}$ http://www.ioc-unesco.org/ (last access: 9 November 2018).

${ }^{14}$ https://www.irso.info/wp-content/uploads/International_RV_ Code_final.pdf (last access: 9 November 2018).
}

vi. introducing policies and regulations for ocean acoustics governance.

Yet, the annual use of certain expendable tools is unavoidable (e.g. XBTs, artificial weights, lost mooring chains) as the benefits of the observations they support are widely believed to outweigh the impacts. The design of devices and sensors such that they can be broken down for recycling and the recovery of valuable or potentially toxic elements is a major challenge to be considered in the future.

In geophysics, the investigation of the sea floor has an impact on marine fauna, but recommendations have been made to minimize the noise impact (e.g. slowly ramp up the sonar from low to high power over 10 to $20 \mathrm{~min}$ to avoid potentially harmful startle and/or stress responses in animals; give mobile animals the time to leave a survey area; allow vessels or observers to check for whales and switch off sonar systems when mammals are around). Air guns are commonly used by the oil and gas exploration industry but also by researchers for mapping the structure and stratigraphy of the sea floor (sediment layers, change in sediment layers, basal geology $)^{15}$. The emissions may be powerful enough to kill or physically injure some animals and can change animal behaviour, distribution and habitat use (Normandeau Associates Inc., 2012; Popper and Hastings, 2009; Wardle et al., 2001). Sound source technology is evolving: now marine vibrators have been designed that meet survey needs but produce a continuous, lower volume of noise that should be not as harmful as air guns, but the technology is currently very expensive and requires training and investment (equipment, software), inhibiting its uptake. A combination of regulations and financial incentives may be required to see this technology adopted more widely.

Shipping, including research vessels, is also heavily contributing to ocean noise (e.g. McKenna et al., 2012). As new ships are constructed, they should include the most current design features and other technologies that dampen the noise they emit (Southall and Scholik-Schlomer, 2008).

The main recommendations regarding nature conservation and avoiding environmental impacts are the following.

- Ensure that sampling sites are not impacted on a large scale and/or irreparably damaged.

- Research activities must not impede the conservation of marine biodiversity.

- Ensure priority is given to non-destructive sampling techniques and, where environmental damage is unavoidable, provide the means for restoration.

\footnotetext{
${ }^{15}$ Air guns generate intense omnidirectional, low-frequency (20$200 \mathrm{~Hz}$ ), repetitive (every 10-15 s) sounds (Hawkins et al., 2014; Popper et al., 2014), whose reflections are recorded to generate 3-D maps to varying depths of the substrate.
} 
- Plan science activities carefully to anticipate unintended, potentially harmful impacts and avoid them before they occur.

\subsection{Compliance with laws}

At the global level, the United Nation's Convention of the Law of the Sea (UNCLOS, 1982) provides a comprehensive structure for dealing with human activities in the oceans and the legal framework to regulate key aspects of resources in the sea and uses of the ocean. These include navigational rights, territorial sea limits, economic jurisdiction, the legal status of resources on the seabed beyond the limits of national jurisdiction, passage of ships, conservation and management of living marine resources, protection of the marine environment, marine research regimes, and binding procedures for the settlement of disputes between states ${ }^{16}$. The aim is to facilitate marine scientific research, balance the interests and rights of coastal states with those of other states in the international community, and promote, inter alia, the equitable and efficient utilization of their resources. UNCLOS defines zones of coastal jurisdiction, for which states have different rights and duties in each separate sector (UNCLOS, 1982). These are more specifically outlined below.

- The territorial sea links ipso jure to the territorial sovereignty of the coastal state from the baselines to a limit of 12 nautical miles (UNCLOS, Art. 3), which includes a right of innocent passage for ships of all states (Article 17).

- The exclusive economic zone (EEZ) is an area in which the coastal state may claim exclusive rights for the exploration and exploitation of marine resources over 200 miles from the baselines (UNCLOS, Arts. 57 and 58).

- The continental shelf comprises the submarine seabed and its subsoil beyond the limits of the territorial sea; within 200 miles from the baselines up to 350 miles, it is related ipso jure to sovereign rights on natural resources.

Marine scientific research in the exclusive economic zone and on the continental shelf may be carried out with the consent of the coastal state (UNCLOS, Article 246), specifying the nature and timing of the research (the data collected may be of different natures: biological, environmental, oceanographic, hydrographic, geophysical or geological; UNCLOS, Article 248). Within their national jurisdiction, states are required to manage the use of ocean space and resources for their own benefit, but their responsibility goes beyond this and UNCLOS commits them to contribute to the achievement of a just and equitable international economic order

\footnotetext{
${ }^{16} \mathrm{http} / / / w w w . u n . o r g / d e p t s / l o s / c o n v e n t i o n \_a g r e e m e n t s /$ convention_historical_perspective.htm\#HistoricalPerspective (last access: 13 November 2018).
}

that takes into account the interests and needs of all humanity (Prue, 2011). In areas beyond those recognized as falling under a nation's jurisdiction (areas beyond national jurisdiction $-\mathrm{ABJN}$ ), any resources present are viewed as belonging to the global commons because no national entity can claim sole jurisdiction under international law. To avoid conflicts and attempt to provide sound management regimes for resources in ABNJ, some international treaties have been negotiated. Examples include the International Whaling Commis$\operatorname{sion}^{17}$, the International Seabed Authority ${ }^{18}$ and the Antarctic Treaty System ${ }^{19}$. More recently, the UN has adopted a resolution regarding marine genetic resources in the high seas through an international legally binding instrument under UNCLOS dealing with the conservation and sustainable use of marine biological diversity in areas beyond national jurisdiction ${ }^{20}$. This lays out the obligations of the signatories and will change the use of marine biological resources in the future in the open sea. In coming years, scientific evidence will be essential for this instrument (MPAs, environmental impact assessment, genetic resources and knowledge transfer, etc.)

The Convention on Biological Diversity is dedicated to the conservation of biological diversity, the sustainable use of its components, and the fair and equitable sharing of benefits arising from the use of genetic resources. The Nagoya Protocol on Access to Genetic Resources and the Fair and Equitable Sharing of Benefits Arising from their Utilization (ABS) to the Convention on Biological Diversity (CBD) is a supplementary agreement to the CBD. It provides a transparent legal framework for the effective implementation of one of the three objectives of the CBD: the fair and equitable sharing of benefits arising from the utilization of genetic resources. The Cartagena Protocol on Biosafety to the $\mathrm{CBD}$ is also an international agreement which aims to ensure the safe handling, transport and use of living modified organisms resulting from modern biotechnology that may have adverse effects on biological diversity, also taking into account risks to human health. Compliance with these protocols while working on biological resources is fundamental.

With regard to the protection of the marine environment, many international obligations emanating from the United Nations and other bodies exist, sometimes overlapping regional conventions and policies as well as EU legislation. Regional conventions have been designed to protect the marine environment from human activities in specific regional seas: the Black Sea (Bucharest Convention, 1992), the Mediterranean Sea (Barcelona Convention, 1995), the Baltic Sea (Helsinki Convention, 1992), the Atlantic (OSPAR Convention, 1992), the South Pacific (Nouméa Convention, 1986),

\footnotetext{
${ }^{17}$ https://iwc.int/home (last access: 9 November 2018).

18 https://www.isa.org.jm/ (last access: 9 November 2018).

${ }^{19}$ https://www.ats.aq/index_e.htm (last access: 9 November 2018).

${ }^{20} \mathrm{UN}$ resolution 69/292 of 19 June 2015.
} 
the East Sea (Kuwait Regional Convention, 2012) and the Red Sea (Jeddah Convention, 1982), with extensions to a wider geographical area (the London Convention, 1972 and the Bonn Convention, 1979). Moreover, in the last 50 years, the EU has adopted more than 200 directives, regulations, and many other forms of legislation and amendments that have direct repercussions for marine environmental policy and management, resulting in a patchwork of EU legislation and leading to a piecemeal approach to marine protection that tends to evolve in more simplified ways (Boyes and Elliott, 2014).

For ocean scientists, it is thus important to clearly identify obligations, regulations and laws governing access to and utilization of ocean resources including for study purposes under national jurisdiction and any other agreements, treaties or conventions at the international, regional and national levels. This might be a growing issue in coming years, especially regarding access to both biological resources and calls for open access to biological data. To prepare for this, national legislation and national contacts must be clearly identified, and principle 5 (reciprocal relationships; see below) must apply. Academic and research organizations or universities in the future will need to strongly support and help scientists with legal and ethical expertise to facilitate their research.

The main recommendations concerning compliance with laws are the following.

- Ask your institutions or organizations for help in clearly identifying the regulations that may apply to your research activities (environment, Nagoya Protocol, guidelines, etc.).

- Make sure you comply with these regulations, especially domestic laws.

- Adopt a transparent attitude during negotiations related to access to and use of biological resources.

- Keep track of your activities when you access biological resources in the sovereign waters of a country.

- Honour the spirit of the CBD, the Nagoya Protocol, and other relevant international and global agreements.

\subsection{Reciprocal relation and cultural respect}

A reciprocal relationship is one in which each party bears a responsibility for the welfare and/or well-being of the other. The stability of the relationship comes from the extent to which those responsibilities are balanced. In some sense, each person earns rights because of responsibilities to the other. Sustainable scientific exchange requires mutual respect for human diversity and different cultures, which is a fundamental right highlighted in the Charter of Fundamental Rights of the European Union and the European Code of Conduct for Research Integrity. The Singapore statement on research integrity (Resnik and Shamoo, 2011) defines common standards while acknowledging the differences among nations (political, cultural, social and political) to promote ethical conduct among scientists. It includes four principles (honesty, accountability, professionalism and stewardship) and 14 responsibilities for the ethical conduct of research. These core values are recalled by the Montreal statement on research integrity in cross-boundary research collaborations (2013). This statement provides recommendations for individual and institutional partners when collaborating at the international level. It highlights global core values such as integrity and trust but also, more specifically, ethical values while managing a collaboration such as agreements, communication, transparency and monitoring. The CIESM Charter for Access and Benefit Sharing arising from the use of marine genetic resources also addresses data integrity, data sharing, record keeping, authorship and complying with regulations (Barbier and Briand, 2014)

In 2013 the European Union, the US and Canada recognized "the importance of the Atlantic Ocean to our citizens, prosperity, human health and well-being, adaptation to climate and other environmental change, and security"21 . They signed the Galway statement on Atlantic Ocean cooperation and in 2017 the EU, Brazil and South Africa signed an accord that states the following: "Oceans play a key role in developing national and regional economies, achieving the Sustainable Development Goals, and addressing climate change" 22 In the context of developing a strategy for sustainable Atlantic observing systems, other countries overlooking the Atlantic Ocean will be invited in the future to collaborate. For future development, the role and responsibilities of each party must be clearly established based on a mutual understanding with resolutions provided when conflicts occur. Of course, the responsibilities for the outcomes of research are also essential in international cooperations such as agreement regarding data, intellectual property and research records or publication, authorship, and acknowledgement.

To engage in a trustful relationship, keeping track of data and information and being transparent also facilitates the flow of communication: the scientific objectives and the proposed research (scientific prospection or commercial exploitation) should always be well defined and communicated to collaborators. Sometimes, in inter-sectorial, multidisciplinary research, the common definition and harmonization of terms might be useful. The role of each partner needs to be clearly defined and understood. Written agreements can set out the terms and conditions for transparent procedures and cooperation (CIESM Charter; Barbier and Briand, 2014).

\footnotetext{
${ }^{21}$ Galway statement on Atlantic Ocean cooperation, 2013 (https://ec.europa.eu/research/iscp/pdf/galway_statement_atlantic_ ocean_cooperation.pdf, last access: 9 November 2018).

${ }^{22}$ Belém statement on Atlantic research and innovation cooperation, 2017 (http://ec.europa.eu/research/iscp/pdf/belem_statement_ 2017_en.pdf, last access: 9 November 2018).
} 
The main recommendations for building trust in international collaborations are the following.

- Adopt the Montreal Declaration and the Singapore Declaration on research integrity, including honesty, accountability, professionalism and stewardship.

- Be transparent at all times and communicate about your activities and the partners and/or third parties involved in a project, whatever their origin (private or public), for commercial, applied or fundamental research.

- Communicate the objective of the project, whether commercial or for scientific research, and be flexible.

- Clearly identify the benefits for each party.

- Clearly define the role of each partner, and use written consent if necessary.

- Be respectful and open-minded.

\subsection{Equality and fairness}

Major disparities exist around the world, which has repercussions on marine research. Some parts of the world do not have the infrastructure for an adequate collection of information about their local marine environment and are disadvantaged (Nakicenovic et al., 2016; UN report on data, 2014; Bernal and Simcock, 2016). The ocean observation research communities, specifically in developed states with significant funding for their research and infrastructure, need to be aware of the issues encountered by low-income communities with less infrastructure and lower budgets, who have limited possibilities for participation in decision-making processes (Wyss and Peppoloni, 2016). Sharing expertise and infrastructure would be an asset in capacity building as recalled during the high-level conference at UNESCO entitled "From COP21 towards the United Nations Decade of Ocean Science for Sustainable Development (2021-2030)", 10-11 September $2018^{23}$. As oceans and seas are interconnected, local information is an integral part of a global understanding of ecosystem functioning. Equality is an essential component of planetary stewardship, and equality and sustainability are linked (Steffen and Stafford Smith, 2013; Wilkinson and Pickett, 2010). Scientists have an ethical responsibility to share infrastructure, resources and data.

In the context of developing a strategy for sustainable Atlantic observing systems, the issue of mutual respect for diversity and cultures is a key ethical issue, as more Atlantic coastal countries will be invited to join this expanding network, as called for in the Belém statement.

The term invited is important: sustaining collaborations has been unsuccessful or problematic in the past when developed states have decided on what would be done, where and

\footnotetext{
${ }^{23} \mathrm{https}$ ://en.unesco.org/ocean-climate-conference (last access: 9 November 2018).
}

how. The participation of and consultation with local scientists when research activities are carried out in their local environment is of course a key principle, but their consultation should be done prior to designing any new projects. The involvement of local scientific communities must be done in a mutual relationship to identify, discuss and negotiate the best way to share data, non-monetary benefits and the exchange of mutual benefits, specifically when exploring marine biological resources (CIESM Charter; Barbier and Briand, 2014). A good example is the PIRATA network based on collaborations among France, Brazil and the USA. These very different cultures have established a long-lasting, mutually beneficial partnership that has also helped the global community since the mid-1990s. PIRATA has established itself as the reference network of oceanic and atmospheric observations in the tropical Atlantic Ocean, supporting dedicated climate research and operational climate and ocean prediction.

An ideal approach would involve not only scientists, but also all stakeholders involved such as governments, civil society, NGOs and economic actors. The concept of co-design could be applied. The co-design approach has been developed from participatory design techniques in Scandinavia in the 1970s into creative practice. Co-design is a term referring to participatory co-creation and open design processes and includes a wide range of people to make a creative contribution in the formulation and solution of a problem. This concept could be applied to research when the co-designers come from low-income countries and/or developing states with their culture, means of reflection, ideas and traditional knowledge of their coasts. To deepen this principle, traditional knowledge should be incorporated in the overall understanding of the ocean. Traditional knowledge is carried by ocean end users such as fishermen, harvesters, divers and sailors. They have a deep knowledge of the local environment and can help in identifying emerging issues. It is up to the scientific community to validate this traditional knowledge (Bernal and Simcock, 2016).

Viewed more broadly, our science community, which is funded by public resources, could be viewed as having an ethical obligation to involve in research and monitoring the different users of the maritime space, such as governments, civil society, NGOs and economic actors. This would improve study designs and execution by incorporating historic, local and/or traditional knowledge from different knowledge systems and make new resources available, directly inform users about the research to be conducted along their coast, and perhaps stimulate their interest to participate (State of the Marine Environment: Trends and Processes, UNEP-GPA, 2006) because "preserving the diversity of ways of understanding the natural world and of co-inhabiting with is an essential aspect of the stewardship of both local places and the entire Earth" (Rozzi et al., 2015). This participatory approach requires the establishment of mutual engagement and respectful, open-minded interaction with the locals (Wyss and Peppoloni, 2016; Rozzi et al., 2015). For example, har- 
vesters could also deploy or recover instruments or record data, improving the precision and accuracy of planned scientific studies. It is difficult to defend the ethics of not taking available steps to improve our science. In truth, such engagement has long been implemented in some countries, although the motivation has tended to be a lack of budget to conduct research. Actions have included replacing cruises on research ships with accompanying crews on military or harvester vessels.

The main recommendations for building trust in international collaborations are the following.

- Be transparent at all times and communicate about your research activities.

- Accept the differences between ocean observing communities; respect local culture and resources.

- Be respectful and open-minded with the locals.

- Engage in discussions with those who hold traditional knowledge or who use the ocean daily.

\subsection{A governance adapted to socio-ecological systems}

With the Anthropocene, we have also entered a new era of global governance, which has brought an end to top-down policymaking in goal-setting processes. This is illustrated by the international institutional governance that is joining forces to achieve a global goal: the SDG process and the Paris Agreement. For governing global commons in the Anthropocene, three new principles have been proposed by $\mathrm{Na}-$ kicenovic.

1. The inclusivity principle states that our resources are not external to human activity; they are internal to development at all scales and must be treated in an inclusive manner.

2. The university principle requires a paradigm shift in the vision of the human world towards global management.

3. The principle of resilience aims to safeguard the stability of the Earth.

The resilience of socio-ecological systems has recently been proposed by Biggs et al. (2012) and summarized by Nakicenovic et al. (2016).

A complex adaptive thinking system is embedded within the proposed principles, which involves management approaches that accept unpredictability, uncertainty and range of motion rather than rigid control. Continuous learning with broad participation enhances legitimacy and expands the depth and diversity of knowledge. The governance system might change in the future. Rozzi predicts that "Anthropocene governance will involve more diverse stakeholders than the type of governance we have been used to. This is tied to education, knowledge and empowerment. Science is alike to become more active and leave its ivory tower to engage more intensely with other stakeholders". Science is a strong voice of the environment in terms of governance. At the UNESCO High-Level Conference on the Ocean Decade (2018), the importance of an interface between policy and science was reiterated through consultations and discussions between the two parties, particularly on climate change. The role of the oceans in the resilience and stability of the Earth system must be acknowledged. Common indicators could be developed to integrate the oceans into policy priorities: economic, social and environmental indicators (N. Hilmi, personal communication, 2018).

Governance includes the responsibility to manage and protect the global commons, and the stability and resilience of the Earth system depend on it. The "global commons" refers to resources that belong to the international community as a whole and are not uniquely subject to the national jurisdiction of a particular state. Fortunately, the fact that this stability and resilience is dependent upon both the global commons and the resources within national jurisdiction has been recognized under both national and international laws (Nakicenovic et al., 2016).

Ocean observing platforms are operating globally, providing extensive physical, chemical and biological data which tremendously improve our understanding of how the marine environment works and how the ocean is presently changing. With the rapid development of open-access data platforms, the scientific community is becoming increasingly engaged in sharing data and in knowledge transfer. These data are perhaps the most valuable common resource that ocean scientists produce and need to be managed in a coordinated and ethical way. The scientific community should ensure that its contributors share responsibilities for data preservation, delivery and management based on recommendations. The adoption of the data FAIR (findable, accessible, interoperable and reusable; Wilkinson et al., 2016) principles goes a long way to meeting this requirement. Any information related to the research activities handled by one party should be shared with the other parties unless an international organization is gathering data, which avoids national political influence on data infrastructure, such as JCOMMOPS, IHO, OBIS, EMODnet or ARGO.

Of course, governance calls for clear, transparent and traceable procedures regarding the use of natural resources and knowledge, which should be described in any agreement to avoid conflicts of interest (Barbier, 2016) because accurate and reliable information on the state of a resource for all users is critical (Nakicenovic et al., 2016). In collaborative research, responsible research and innovation principles require that conflicts not be used to generate unfair advantages or benefits for one or several parties over the others. As noted by Barbier (2016), "conflicts occur when people perceive that, because of disagreement, there is a threat to their needs, resources, interests or concerns. Participants in conflicts tend to respond on the basis of their perceptions of the situation, 
rather than an objective review of it. People filter their perceptions (and reactions) through their values, culture, beliefs, information, experience, gender and other variables. Conflict responses are both filled with ideas and feelings that can be very strong and powerful guides to our sense of possible solutions. It is important to anticipate conflicts and regarding access to resources, traceability and transparency in conducting research are important factors".

For ocean science research, the data produced and their potential for misuse or to provide an unfair advantage is a potential ethical friction point, which may need to be addressed in some studies.

In the interest of both traceability and transparency, scientists and the national authorities with jurisdiction over where the work is being conducted must all develop and agree to a common understanding of the polices and terms that regulate access to data repositories or biorepositories. When third parties (such as private industry) beyond the science team and national hosts are involved in a project, it is imperative that the project leads clearly communicate to participants and stakeholders who the third parties are, describe what their role is in the proposed research and inform participants about any changes in a timely manner. Traceability and transparency for the data and study processes can help defuse the potential for undesirable conflicts.

Capacity building is also an important issue in governance and scientific responsibility also rests on the training of young people. Initiatives such as the Partnership for Observation of the World's Oceans and POGO programmes (Partnership for Observation of the Global Oceans ${ }^{24}$ ) are important in that they implement training programmes for young people, offer places on joint cruises to strengthen collaboration and allow trainees at all stages of their careers to learn new methods. The training of youth is important as they will be the future generation of researchers who will pursue a global effort that will be more advanced on larger scales than scientists have undertaken in the past. Within the AtlantOS Horizon 2020 Ocean Science Project, a platform for early-career scientists (ECSs) has been created to promote the exchange of ideas and experiences and to discuss the development of potential future initiatives. Within the platform, issues and scientific topics can be discussed with peers at a very similar career stage. It is valuable to include ideas that are shaped through intergenerational cooperation; it improves internal and potentially boosts external communication. As a result, within AtlantOS there is (1) a representative ECS in the steering committee for the project and (2) a representative ECS on the gender diversity board. Such linkages should be promoted and encouraged. These ECSs will also bring a fresh perspective on existing ethical issues and provide guidance to all on new and unanticipated ethical issues that may arise in the future.

\footnotetext{
${ }^{24}$ POGO: http://www.ocean-partners.org/ (last access: 9 November 2018).
}

Civil society engagement has the potential to inform and sensitize society through education and direct participation in an action. Contributions from citizens can range from collecting data and information to data analysis and can be based on incidental observations as well as on standardized surveys and monitoring protocols. With the technological advances in automated systems, marine measurement equipment and digital capabilities (smartphone apps, drones, etc.) are continuously improving, offering new ways to conduct data collection and analysis in "citizen science" projects (EMB Policy brief, 2017). Integrating their participation might be relevant for some research observations and should be seriously considered. It is up to the scientific community to validate these data.

The main recommendations for the adoption of a new mode of governance are as follows.

- Strengthen clear, transparent and traceable procedures.

- Adopt the FAIR concept for data (findable, accessible, interoperable and reusable) and share responsibility for data preservation, delivery and management.

- Accept unpredictability, uncertainty and range of motion rather than applying rigid control.

- Adopt principles of responsible research and innovation.

- Develop training activities, which must be adapted to the trainees' level of knowledge.

- Support capacity building to integrate local knowledge about the ocean into a global understanding of our oceans.

- Integrate early-career scientists into governance processes.

- Consider civil society as a potential actor in the ocean observing system, and build a bridge with scientists if necessary.

- Integrate social scientists into the design of a project to develop a survey on traditional knowledge in the local environment.

\subsection{Animal ethics in ocean observation}

Working with animals brings a suite of ethical problems particular to biology (as opposed to physical or chemical oceanography). Marine animals are a focus of research and monitoring for a variety of reasons. Most marine species are viewed as a resource, and the economic and social wellbeing of many coastal communities depends on the health of marine animal populations for fisheries, tourism and other reasons (NOAA, 2018). This imposes a moral obligation on managers and the scientists who provide them with evidence 
to provide and use research knowledge to manage these resources sustainably for the good of the human communities who depend on them. The development of sophisticated satellite-linked environmental sensors has enabled scientists to piggyback on the movements of certain free-ranging, typically large marine animals (mostly pinnipeds; Hussey et al., 2015). These animals sample ocean areas that are inaccessible or unaffordable to sample with our current technologies (e.g. under ice sheets in polar areas) and provide data that can be of great benefit for humans (e.g. enabling more accurate climate and weather forecasting and a better understanding of ocean circulation; Roquet et al., 2014).

However, the use of animals for research has generated a widespread, passionate and evolving debate surrounding animal sentience, their rights and the responsibilities of humans towards animals (e.g. Rollins, 2002). There is broad acceptance internationally that animal research needs to be conducted humanely.

The Ocean Tracking Network (OTN) is a major global animal research network charged with using electronic telemetry to document the movement and survival of marine and freshwater animals. OTN maintains major research infrastructure in both the North and South Atlantic Ocean. The information generated by OTN researchers serves a variety of conservation and management purposes for aquatic species (Hussey et al., 2015).

Ethical issues facing OTN researchers include obligations to the animals and obligations to the broad group of stakeholders interested in the results from OTN studies and access to OTN data.

With regards to obligations to animals, these address animal welfare considerations when the animals are used in research. Given that OTN researchers and their research projects originate in different countries, studies typically follow animal welfare guidelines and requirements in the country that originates (funds) a tagging study. This usually involves submission of an animal ethics protocol to the investigator's host institution, whereby it is reviewed by an animal care committee composed of experienced researchers, veterinarians and trained technical staff. These committees work according to national animal care standards (for example, in Canada this is the Canada Council for Animal Care) and review the proposed work for the levels of distress that could be caused to the animals by their capture, handling and tagging (including the stress of the capture methods, the burden that the size and/or weight tag will impose on the animal, use of proper anaesthetic and aseptic surgical procedures, oxygenation-aeration provided to the animals, the training and speed of surgeons, availability of proper recovery facilities, and release of the animals back to the wild at a time and place that minimizes predation risk). The possibility of using substitutes for the animals in the research is also reviewed (e.g. tissue culture, model simulations; not an option when the objective is documenting the movements and survival of free-ranging animals), as is whether the investigators are using the minimum number of animals needed to conduct a valid study. Should the investigators fail to address these issues to the satisfaction of the animal care committees, they will be refused animal care certificates and/or scientific permits to conduct their work, and funding agencies will not support the research.

With regards to making knowledge and data from tracking studies available, tracking scientists regularly present their results through peer-reviewed publications, scientific reports and presentations. There is also growing recognition that the data from publicly funded research should be made publicly available. While the science community is moving toward accepting this (Nguyen et al., 2017), the mechanics and cyberinfrastructure necessary to deliver the capability is still in development. However, debate continues on how fast the data should become available. Most telemetry organizations have adopted policies that implement a time delay (1-2 years) before data can be made public (unless the originators of the data agree to earlier public release). This is to, among other concerns, protect the rights of students to finish their research projects. In addition, there are ethical issues associated with the potential for misuse of the public data, such as the provision of the real-time locations of highly valued and possibly endangered species to poachers (see Cooke et al., 2017).

The main recommendations for respect for animals in ocean observing systems are as follows.

- Ensure the animal's good health: identify the levels of distress that could be caused to animals by their capture, handling and labelling, and provide means to mitigate these problems; use appropriate anaesthesia and aseptic surgery procedures, oxygenate-air the animals, ensure that surgeons are trained and perform their tasks quickly, use appropriate recovery facilities, and return the animals to the wild at a time and place that minimize the risk of predation.

- Make sure there is no other choice to do your research.

- Identify the competent authority in the country where the research activities are carried out and provide all relevant information regarding the handling of animals in the context of the project.

- Ensure that the dissemination of data does not affect the survival of animals, in particular highly endangered species.

- Do not misuse the data.

\subsection{Transfer of knowledge}

The Cape Town statement calls for the promotion of geoeducation and outreach for all (Di Capua et al., 2017). This principle can be interpreted in different ways: (a) promoting communication towards society which comprises all outreach activities, such as the Ocean Literacy programme in 
France (Sorbonne University) or "Friday's research club" (GEOMAR) and Kiel research workshops (Kiel University) in Germany, which present many activities for kids around the oceans; (b) promoting communication towards policymakers to provide them with information and means on the state of the marine environment and our fears; (c) promoting the education of the future generation of marine scientists; (d) promoting training activities which can be delivered to senior or young scientists, from high-income or low-income countries, about specific topics in science or about the ethical dimension of the marine sciences; and, finally, (e) promoting civil society engagement through citizen science.

Scientists inherit a societal responsibility to objectively present and represent their data. Previous existing gaps in the ability to communicate research results to the general public are no longer present today. Each scientific project sponsor requires a communication strategy and a knowledge transfer plan to the public at large. But gaps persist in the ability to integrate the results of scientific research into policymaking. Hansson (2002) defines the difference between data, information and knowledge: "Data differs from information in the extent that it doesn't need a form that lends itself to assimilation. If, instead of a book, I read the tens of thousands of questionnaires on which this book is based, I would be looking at data instead of information. In short, data must be processable in order to be considered as information and assimilated in order to become knowledge." In ocean observation, data are elements coming from sensors and observation, and they are relative to the measured level of any variables. Information consists of data organized in a given structure and which, placed in a context, are endowed with meaning. Knowledge goes further: it makes predictions to establish causal links or make decisions (Bohn, 1994). Earth stewardship requires that scientists engage not only in the production of this knowledge, but also in meeting societal requirements for education and governance (Rozzi et al., 2015).

Interaction with policymakers is evolving and will become commonplace as the Anthropocene era is based on scientific evidence. Science and policy interface is essential at the national level but also at the regional and global level (Bernal and Simcock, 2016). But the clear identification of roles and responsibilities is necessary in the decision-making process, especially in risk prediction: cooperativeness between institutions must be strengthened to avoid biased, contradictory or confusing information (Wyss and Peppolonini, 2016).

In this sense, AtlantOS has actively worked and proposed many collaborations to address our oceans in an integrated, transdisciplinary, cross-sectoral and responsible manner: the most recent action is participation in drafting the policy brief recently edited by Blue Action ${ }^{25}$ on the slowing Gulf Stream and potential impacts (Olsen et al., 2018). Blue Action (Arctic Impact on Weather and Climate) is a research and inno-

\footnotetext{
${ }^{25}$ https://zenodo.org/record/1408097\#.W44yBfZuKIU.e (last access: 9 November 2018).
}

vation action which aims to improve our ability to describe, model and predict Arctic climate change and its impact on Northern Hemisphere climate, weather and their extremes, and to deliver valuated climate services of societal benefit. The policy brief on the Gulf Stream will be discussed during a science policy event at the European Parliament. AtlantOS has been also actively involved in strategic and political debates and social science activities such as the UN Ocean Conference on Sustainable Development Goal 14, the UN COP 23 meeting, the Vision 2030 for ocean observing in Europe meeting, and the initiation of the BluePrint group for ocean observation implementation and vision.

Ethical behaviour in science should be encouraged and its teaching should become a common requirement at all stages of education process. Ethical behaviour is essential and even natural for scientists in carefully measuring, using appropriate standards, repeating the measurement, assessing uncertainty, and reporting data and uncertainty so that others can examine them (Bobrowsky et al., 2017). This is because the practice of science involves uncertainty. As noted by Bobrowsky, "scientists seek knowledge that stands up to tests of experience and time".

Matteucci (2014), drafted an oath for all geoscientists the "geoethical promise" - that could be used as a tool and a personal commitment for individual geoscientists to better address the economic, social, cultural and economic dimensions of geoscience. This oath could easily be adopted by the ocean observing community.

Teaching geosciences and oceanography-marine science is also essential. It is crucial to support and educate schoolchildren and pupils to provide them with a certain notion of the oceans concerning their damage related to human activities. Fundamental notions of ethics should be taught along with the science of truth, uncertainty and ethics in science (Bobrowsky et al., 2017). For non-specialized undergraduate students, a programme on marine resources, ocean components, interconnectivity and the resilience of the Earth could be integrated into traditional educational programmes (such as math, languages, geography). Of course, future scientists, geologists or marine ecologists must learn and understand these concepts, but anyone living on Earth should have a clear vision of our Earth system. These students will grow up and become actors in society. Among them are future decision-makers at the political or institutional level in international, national or regional organizations, programmes or projects as engineers or consumers. This global education would benefit society as a whole by creating leaders with a global understanding of the Earth system.

More generally, training is defined as a key core value of any ethical guidelines as it creates and generates a capacity to implement and transfer a set of standard methods or documented best practices (Costello et al., 2016). Training is strongly linked to capacity building. Capacity building is essential for developing observations in areas where they do not exist and could facilitate the interoperability of 
data collected by different people through different means (Muller-Karger et al., 2018). In capacity building, the place of young scientists is important, and some programmes are implemented to train and offer access to cruises for earlystage researchers. The POGO and PIRATA programmes offer seats for joint cruises and host exchanges to reinforce collaboration and learning established and new methodologies. These missions offer a unique opportunity to expose students to an intensive working atmosphere, to forge professional relationships between students, junior and senior scientists, and to understand different cultures and international differences in knowledge generation, communication and use.

Besides obligatory and voluntary practical training for students and doctoral and postdoctoral researchers in marine sciences or related fields, workshops or forums for the presentation of cutting-edge, current marine hot topics should include discussions of ethical issues. This has been developed in France, and some universities (Lyon, Bordeaux) have proposed massive open online courses (MOOCs) on the ethics of research. The ethical practice of science should be emphasized throughout the marine early-career scientist curriculum, as should the oath for geoscience.

The main recommendations for knowledge transfer are as follows.

- Integrate experts to establish a dialogue with policymakers.

- Train the next generation of scientists and integrate fundamental ethical values into this training.

- Foster the transfer of knowledge to non-experts, such as pupils and undergraduate students.

- Include in your science communication a clear message about everyone's responsibility for the stewardship of the oceans and land.

\section{Management and recommendations to apply ethics in research projects}

"The free and responsible practice of science is fundamental to scientific advancement and human and environmental well-being. Such practice, in all its aspects, requires freedom of movement, association, expression and communication for scientists ${ }^{26}$ " (ICSU, 2014). The role of science project managers is to support and accompany scientists in their research, to effectively demonstrate progress on research tasks, to provide fit-for-purpose products, to acknowledge various cultures and values, and to secure budget availability and societal usability. Results from a project on environmental and Earth research infrastructure in Europe (ENVRIplus

\footnotetext{
${ }^{26}$ The Principle of Universality (freedom and responsibility) of Science, ICSU, 2014.
}

project $^{27}$ ) clearly show that scientists are not aware of the ethical and social implications of their work (Peppoloni et al., 2017). As a consequence, the science project manager has to drive the attention of scientists toward some issues not directly linked to scientific matters, such as reasonable compromises, ethics, responsibility and cohesion among the fundamental principles of ethics in their scientific approach (Bobrowsky et al., 2017). The Cape Town statement with clear core values has been translated into 18 different languages (Peppoloni, 2018) and should be promoted to a wider community of geoscientists, including marine scientists.

Science management should become an instrument to ease the implementation of an ethical approach within a project.

In addition, the ocean observing community should collaborate to establish its own ocean ethics principles recalling geoethics fundamental principles and providing ethical guidelines. Then, it would be the role of the manager to promote these guidelines and contribute to sensibilizing scientists to their responsibility toward society and the marine environment.

There are different ways to integrate applied ethics into the management of scientific projects by considering the severity of the ethical issues identified. If a proposed project does not raise important ethical issues, a task highlighting an ethical approach could be integrated in different work packages (WPs), either through training programmes or during conferences on the topic of the WP. Courses dedicated to earlystage scientists should integrate ethical approaches and codes of conduct surrounding key issues that will be examined by a project. This will highlight ethical obligations and encourage responsible research. Including talks regarding ethics or philosophical approaches in conferences or in seminar series would also be a good way to make scientists aware of ethical issues and to invite them to reflect on such issues.

By nature, some scientific topics are more controversial and prone to ethical issues than others: for example, clear and serious ethical issues can be identified and raised in deep sea mining (Miller et al., 2018). In such cases it might be wise to dedicate WP tasks or an entire WP to ethics to properly integrate them into the project design. The ENVRIplus H2020 project dedicated a WP aiming to develop an ethical framework for research infrastructure. The goal of this WP is to increase awareness of the importance of ethical aspects in Earth sciences as a whole for both scientists and the public. Implementing such a WP in a project would provide direction and focus for the network around ethical issues by, for example, proposing tasks such as organizing round tables or focus groups (with scientists, philosophers, social scien-

\footnotetext{
${ }^{27}$ ENVRIplus is a Horizon 2020 project bringing environmental and Earth system research infrastructure, projects and networks together with technical specialist partners to create a more coherent, interdisciplinary and interoperable cluster of environmental research infrastructure across Europe (http://www.envriplus.eu, last access: 11 November 2018).
} 
tists, etc.) that could think about methodologies to overcome some ethical challenges. It might also be wise to seek advice by consulting different stakeholders with various interests to ensure that all dimensions such as politic, scientific, legal and economic are considered. This method would create a collective intelligence and provide potential actions or guidelines for solutions and strategies on how to handle the ethical issues of a project. Communication tools regarding these issues must be developed.

\section{Conclusions}

With the unanimous adoption of the UN SDGs in 2015, human communities have become engaged in transforming our world: the 2030 agenda for sustainable development (UN GA, 2015 28 ) recognized that developed nations must act rapidly to protect the resilience of the Earth system in a just and equal manner for all and for future generations. Humanity has a responsibility in this and scientists should act as stewards for the oceans and the Earth system as a whole. Scientists present scientific evidence through knowledge and the new technology they develop that needs to be integrated into decision-making processes. With this important task, scientists have a responsibility to act in an ethical way and apply all the fundamental ethical principles described in the Cape Town statement: (a) ethical values regarding their behaviour, honesty, integrity, courtesy and fairness; (b) the social values of sustainability, prevention and education; and (c) cultural values to strengthen the relationship between communities (Peppoloni and Di Capua, 2017). The basic criterion of geoethics is responsibility.

Bobrowsky et al. (2017) define four levels of responsibility: (1) individual, (2) towards colleagues, (3) towards society based on our expertise to deliver clear messages to policymakers to minimize anthropogenic damages, and (4) towards the Earth system to maintain its stability and resilience for the future generation. These four levels of responsibility are easy to implement, and the ocean observation community can easily endorse the Cape Town statement and apply the key principles; the marine science community may do well to consider creating a similar approach and adopting geoethical core values or a code of ethics dedicated to research activities relevant to ocean observing activities. The community could extend the geoethics statement to the ocean ethics statement. We must also determine which of the provisions of its code of ethics are strict rules and which are statements of aspiration as recommended by Abbott (2017).

\footnotetext{
${ }^{28} \mathrm{~A} / \mathrm{RES} / 70 / 1$ Transforming our world: the 2030 Agenda for Sustainable Development (https: //sustainabledevelopment.un.org/content/documents/ 21252030AgendaforSustainableDevelopmentweb.pdf, last access: 20 Novembre 2018)
}

Science project managers will be the "guardians of these ethical core values" by implementing them in future ocean observing research projects.

This article is a fist attempt to highlight the core values applicable to ocean observation, which can then be improved and adopted as part of geoethics and the stewardship of the Earth system and become an integrated part of best practices in ocean observing systems. Ethics are the sum of all elements that will enable sustainable research and monitoring endeavours and will include elements drawn from the philosophical, social and natural scientific dimensions. These are summarized below.

- Respecting and minimizing impacts from research and monitoring on ocean ecosystems

- Respecting and engaging local people in research activities from multiple cultures and diverse sectors

- Working with the goal of global benefit based on reciprocal relations, transparency and responsibility

- Maximizing the efficiency and quality of observations in research activities

- Engaging society and communicating with and advising policymakers

- Sharing data: acquire once, use multiple times

- Encouraging learning

Data availability. No data sets were used in this article.

Author contributions. MB initiated the writing of this paper and invited the authors to participate in the writing of certain chapters, discuss concepts, and validate the scientific content.

Competing interests. The authors declare that they have no conflict of interest.

Special issue statement. This article is part of the special issue "Project management in geosciences: systems and practices for high-impact research". It is a result of the EGU General Assembly 2018, Vienna, Austria, 8-13 April 2018.

Acknowledgements. The authors thank Martin Visbeck for encouraging the publication of this paper, Bernard Bourles for his comments and the reviewers for their remarks in helping to improve the quality of the paper. Katsiaryna Pabortsava, Anne-Cathrin Wölfl and Tobias Hahn have received funding from the European Union's Horizon 2020 research and innovation programme under grant agreement no. 633211 (AtlantOS). 
Edited by: Luisa Cristini

Reviewed by: Martin Bohle and one anonymous referee

\section{References}

Abbott, D. M.: Some Fundamental Issues in Geoethics, Ann. Geophys., 60, 7, https://doi.org/10.4401/ag-7407, 2017.

Barbier, M.: Cultural differences in research project management, Geophysical Research Abstracts Vol. 18, EGU2016-5783, EGU General Assembly, 2016.

Barbier, M. and Briand, F.: The CIESM Charter on Access and Benefit-Sharing, a Charter for access to knowledge to everyone and to prevent the abuses of the ocean global commons, available at: www.ciesm.org/marine/charter/index.php (last access: 11 November 2018), 2014.

Barbier, M., Claustre, H., Alonso, P., Bourlès, B., Janssen, F., Lampitt, R., Obolensky, G., Poli, P., Pouliquen, S., Salter, I., Turpin, V., and Woriskey, F.: Blue Print-Synthetic remarks from autonomous observing platforms and Recommendations, 2016, in Report of the AtlantOS workshop on strategies, methods and new technologies for a sustained and integrated autonomous in-situ observing system for the Atlantic Ocean, supported by AORA-CSA, H2020 AtlantOS report, 2016.

Berdinesen, H.: On Han Jonas' "The imperative of responsibility", Philosophia 17/2017, available at: https://philosophia-bg.com (last access: 11 November 2018), 2017.

Bernal, P. and Simcock, A.: Marine scientific Research (2016) Chapter 30, in: The First Global Integrated Marine Assessment, World Ocean Assessment I. Chapter: Chapter 30, Publisher: United Nations, edited by: Inniss, L. and Simcock, A., 2016.

Biggs, R., Sclueter, M., and Schoon, M.: Principles for building resilience, Sustaining Ecosystems Services in Social-Ecological Systems, Cambridge University Press, 2012.

Bobrowsky, P., Cronin, V. S., Di Capua, G., Kieffer, S. W., and Peppoloni, S.: The Emerging Field of Geoethics, in: Scientific Integrity and Ethics with Applications to the Geosciences, edited by: Gundersen, L. C., Special Publication American Geophysical Union, John Wiley and Sons, Inc., 2017.

Bohle, M. and Erle, E. C.: Furthering Ethical Requirements for Applied Earth Science, Ann. Geophys., 60, 1-6, https://doi.org/10.4401/ag-7401, 2017.

Bohn, R. E.: Measuring and Managing Technological Knowledge, Sloan Management Review, Fall, 61-67, 1994.

Boyes, S. J. and Elliott, M.: Marine legislation - The ultimate "horrendogram": International law, European directives \& national implementation, Mar. Pollut. Bull., 86, 39-47, 2014.

Costello, M. J., Basher, Z., McLeod, L., Asaad, I., Claus, S., and Vandepitte, L.: "Chapter 7. Methods for the study of marine biodiversity," in: The GEO Handbook on Biodiversity Observation Networks, edited by: Walters, M. and Scholes, R. J., Springer, 129-163, 2016.

Cooke, S. J., Nguyen, V. M., Kessel, S. T., Hussey, N. E., Young, N., and Ford, A. T.: Troubling and unanticipated issues at the frontier of animal tracking for conservation and management, Conserv. Biol., 31, 1205-1207, https://doi.org/doi:10.1111/cobi.12895, 2017.
De Paiva Toledo, A.: La protection juridique internationale de la biodiversité marine, in Veredas do Direito, Belo Horizonte, 13, 31-62, https://doi.org/10.18623/rvd.v13i27.924, 2016.

Di Capua, G., Peppoloni, S., and Bobrowsky, P. T.: The Cape Town Statement on Geoethics, Ann. Geophys., 60, 1-6, https://doi.org/10.4401/ag-7553, 2017.

EMB Policy brief: European Marine Board, Training the 21st Century Marine Professional: A new vision for marine graduate education and training programmes in Europe, Policy Brief No. 5, 47 pp., 2017.

European Commission: Responsible Research and Innovation - Europe's ability to respond to societal challenges, available at: https: //ec.europa.eu/research/swafs/pdf/pub_rri/KI0214595ENC.pdf (last access: 11 November 2018), 2014.

Gaillard, E.: Crimes against future generations, e-Pública, II, No. 2, 040-062, 2015.

Giuliano, L. and Barbier, M. (Eds.): CIESM, 2011. New partnerships for blue biotechnology development, CIESM Marine Policy Series 1, 52 pp., 2011.

Giuliano, L. and Barbier, M.: Guest editors, Special Issue of Marine Genomics "Omics at the crossroads - from integrated science to multisector implications", Vol. 17, 2014.

Hansson, S. O.: Les incertitudes de la société du savoir, 2002, Revue internationale des sciences sociales: 1 (no. 171), https://doi.org/10.3917/riss.171.0043, 2002.

Hawkins, A. D., Roberts, L., and Cheesman, S.: Responses of freeliving coastal pelagic fish to impulsive sounds, J. Acoustic. Soc. Am., 135, 3101-3116, 2014.

Hussey N. E., Kessel, S. T., Aarestrup, K., Cooke, S. J., Cowley, P. D., FiskISK, A. T., Harcourt, R. G., Holland, K. N., Iverson, S. J., Kocik J. F., Mills-Flemmingand, J. E., and Whoriskey, F. G.: Aquatic animal telemetry: a panoramic window into the underwater world, Science, 348, 1255642, https://doi.org/10.1126/science.1255642, 2015.

ICSU: The Principle of Universality (freedom and responsibility) of Science, available at: https://admin.council.science/app/uploads/ 2017/04/CFRS-brochure-2014.pdf (last access: 11 November 2018), 2014.

IOC-UNESCO: Global Ocean Science Report - The current status of ocean science around the world, available at: http:// unesdoc.unesco.org/images/0023/002354/235406e.pdf (last access: 20 Novembre 2018), 2017.

Jonas, H.: The Imperative of Responsibility: In Search of Ethics for the Technological Age, University of Chicago Press, Chicago, 1979.

Leopold, A.: A Sand County Almanac, Oxford University Press, 129-226, 1949.

Mantatov, Y. and Mantatova, L.: Philosophal underpinnings of Environmental Ethics: Theroy of responsibility by Hans Jonas, 2015, Procd. Soc. Behav., 214, 1055-1061, 2015.

Matteucci, R., Gosso, G., Peppoloni, S., Piacente, S., and Wasowski, J.: The Geoethical Promise: A Proposal Episodes, 37, 190-191, 2014.

McKenna, M. F., Ross, D., Wiggins, S. D., and Hildebrand, J. A.: Underwater radiated noise from modern commercial ships, J. Acoust. Soc. Am. 131, 92-103, 2012.

Miller, A., Thompson, K. F., Johnston, P., and Santillo, D.: Overview of Seabed Mining Including the Current State of Development, Environmental Impacts, 
and Knowledge Gaps, Front. Mar. Sci., 17, 237-251, https://doi.org/10.3389/fmars.2017.00418, 2018.

Miller, M. L. and Kirk, J.: Marine Environmental Ethics, Ocean Coast. Manage., 17, 237-251, 1992.

Montreal Statement on Research Integrity: 3rd World Conference on Research Integrity, Montreal, 5-8 May 2013, available at: http://www.cehd.umn.edu/olpd/MontrealStatement.pdf (last access: 18 June 2015), 2013.

Morand, S. and Lajaunie, C.: Biodiversité et santé, Les liens entre le vivant, les écosystèmes et les sociétés, ISTE Ed. Collection Ecologie, 288 pp., 2018.

Muller-Karger, F. E., Miloslavich, P., Bax, N. J., Simmons, S., Costello, M. J., Sousa Pinto, I., Canonico, G., Turner, W., Gill, M., Montes, E., Best, B. D., Pearlman, J., Halpin, P., Dunn, D., Benson, A., Martin Corinne, S., Weatherdon Lauren, V., Appeltans, W., Provoost, P., Klein, E., Kelble, C. R., Miller, R. J., Chavez, F. P., Iken, K., Chiba, S., Obura, D., Navarro, L. M., Pereira, H. M., Allain, V., Batten, S., Benedetti-Checchi, L., Duffy, J. E., Kudela, R. M., Rebelo, L. M., Shin, Y., and Geller, G.: Advancing Marine Biological Observations and Data Requirements of the Complementary Essential Ocean Variables (EOVs) and Essential Biodiversity Variables (EBVs) Frameworks, Front. Mar. Sci., 5, 211.2018, https://doi.org/10.3389/fmars.2018.00211, 2018.

Normandeau Associates Inc.: Effects of Noise on Fish, Fisheries, and Invertebrates in the U.S. Atlantic and Arctic from Energy Industry Sound-Generating Activities. A Workshop Report for the U.S. Dept. of the Interior, Bureau of Ocean Energy Management. Contract no. M11PC00031, p. 72, 2012.

Nakicenovic, N., Rockström, J., Gaffney, O., and Zimm, C.: Global Commons in the Anthropocene: World Development on a Stable and Resilient Planet, IIASA Working Paper, IIASA, Laxenburg, Austria, WP16019, 2016.

Nguyen, V. M., Brooks, J. L., Young, N., Lennox, R., Haddaway, N., Whoriskey, F. G., Harcourt, R., and Cooke, S. J.: To share or not to share in the emerging era of big data: perspectives from fish telemetry researchers on data sharing, Can. J. Fish. Aquat. Sci., 74, 1260-1274, https://doi.org/10.1139/cjfas-2016-0261, 2017.

NOAA: National Oceanic and Atmospheric Administration (NOAA), Office for Coastal Management 2018, NOAA report on the US ocean and Great Lakes economy, Charleston SC: NOAA Office for Coastal Management, available at: https:// coast.noaa.gov/digitalcoast/training/econreport.html, last access: $11 / 11 / 2018$.

Olsen, S. M., Årthun, M., Eldevik, T., Fritz, J. S., Larsen, K. M. H., Miller, R. G., Moat, B., and Oltmanns, M.: The slowing Gulf Stream? What we know and potential impacts. Blue-Action policy brief. SAMS Research Services Ltd., Konsortium Deutsche Meeresforschung e.V., 2018.

OSPAR convention: Convention for the protection of the marine environment of the north-east atlantic, available at: https://www.ospar.org/site/assets/files/1290/ospar_convention_ e_updated_text_in_2007_no_revs.pdf (last access: 16 November 2018), 1992.

Peppoloni, S.: Spreading geoethics through the languages of the world. Translations of the Cape Town Statement on Geoethics. International Association for Promoting Geoethics (IAPG), available at: http://www.geoethics.org/ctsg (last access: 11 November 2018), 2018.
Peppoloni, S. and Di Capua, G.: Geoethics and geological culture: awareness, responsibility and challenges, Ann. Geophys., 55, 335-341, 2012.

Peppoloni, S. and Di Capua, G.: The Meaning of Geoethics Chapter 1, in: Geoethics: Ethical challenges and case studies in Earth Sciences, edited by: Wyss, M. and Peppoloni, S., Elsevier, ISBN: 978-0127999357, 3-14, https://doi.org/10.1016/B978-012-799935-7.00001-0, 2015.

Peppoloni, S. and Di Capua, G.: Geoethics: Ethical, social, and cultural values in geosciences research, practice, and education: in: Geoscience for the Public Good and Global Development: Toward a Sustainable Future, edited by: Wessel, G. R. and Greenberg, J. K., Geological Society of America Special Paper 520, 2016, ISBN: 978-0-8137-2520-8, 17-21, https://doi.org/10.1130/2016.2520(03), 2016.

Peppoloni, S. and Di Capua, G.: Ethics, in: Encyclopedia of Engineering Geology, edited by: Bobrowsky, P. T. and Marker, B., Encyclopedia of Earth Sciences Series, Springer International Publishing, ISBN: 978-3-319-12127-7, 15, https://doi.org/10.1007/978-3-319-12127-7_115-1, 2017.

Peppoloni, S., Bobrowsky, P., and Di Capua, G.: Geoethics: A Challenge for Research Integrity in Geosciences, in: Integrity in the Global Research Arena, edited by: Steneck, N., Anderson, M., Kleinert, S., and Mayer, T., 336 pp., World Scientific Publishing Co, ISBN: 978-981-4632-38-6, 287-294, https://doi.org/10.1142/9789814632393_0035, 2015.

Peppoloni, S., Di Capua, G., and Haslinger, F.: 2017. D13.1. Questionnaire to analyse the ethical and social issues and assessment report on questionaire answers, ENVRIplus deliverable, 2017.

Popper, A. N. and Hastings, M. C.: Effects of anthropogenic sources of sounds on fishes, J. Fish. Biol., 75, 455-498, 2009.

Popper, A. N., Hawkins, A. D., Fay, R. R., Mann, D. A., Bartol, S., Carlson, T. J., Coombs, S., Ellison, W. T., Gentry, R. L., Halvorsen, M. B., Løkkeborg, S, Rogers, P. H., Southall, B. L., Zeddies, D. G., and Tavolga, W. N.: Sound exposure guidelines for fishes and sea turtles, p. 74., Springer, London, 2014.

Prue, T.: Common Heritage of Mankind Principle, in: The Encyclopedia of Sustainability, edited by: Bosselmann, K., Fogel, D., and Ruhl, J. B., Vol. 3: The Law and Politics of Sustainability, 64-69, Great Barrington, MA, Berkshire Publishing, 2011.

Resnik, D. B. and Shamoo, A. E.: The Singapore Statement on Research Integrity, Account Res., 18, 71-75, https://doi.org/10.1080/08989621.2011.557296, 2011.

Roquet, F. G. Williams, M. A. Hindell, R. Harcourt, McMahon, C., Guinet, C., Charrassin, J. B., Reverdin, G., Boehme, L. S., Lovell, P., and Fedak, M.: A Southern Indian Ocean database of hydrographic profiles obtained with instrumented elephant seals, Scientific Data, 1:140028, https://doi.org/10.1038/sdata.2014.28, 2014.

Rollins, B. E.: An ethicists comments on animal rights versus welfare, Can. Vet. J., 43, 913, 2002.

Rozzi R., Stuart Chapin III, F., Baird Callicott, J., Pickett, S. T. A., Power, M. E., Armesto, J. J., and May Jr., R. H.: Introduction: Linking Ecology and Ethics for an Interregional and Intercultural Earth Stewardship, in: Earth Stewardship Project: Ecology \& Ethics, edited by: Rozzi, R., Chapin III, F. S., Callicott, J. B., Pickett, S., Power, M. E., Armesto, J. J., and May Jr., R. H., 1-14, Springer International Publishing Switzerland 2015, Earth 
Stewardship, Ecol. Ethic., 2, https://doi.org/10.1007/978-3-31912133-8_1, 2015.

Southall, B. L. and Scholik-Schlomer, A.: Final report of the NOAA International Conference: "Potential application of vessel-quieting technology on large commercial vessels", 1-2 May 2007, Silver Spring, MD, USA, 2008.

Steffen, W. and Stafford Smith, M.: Planetary boundaries, equity and global sustainability: Why wealthy countries could benefit from more equity, Curr. Opin. Env. Sust., 5, 403-408, 2013.

UNCLOS: United Nations Convention on the Law of the Sea of 10 December, available at: http://www.un.org/depts/los/convention agreements/texts/unclos/unclos_e.pdf (last access: 11 November 2018), 1982.

UN report on data revolution: UN Secretary-General's Independent Expert Advisory Group on the Data Revolution for Sustainable Development, A World That Counts': Mobilising The Data Revolution for Sustainable Development, 32 pp., 2014.

Violante, R. A., Bozzano, G., ad Rovere, E. I.: The marine environment: hazards, resources and the application of geoethics principles, Ann. Geophys., 60, 1-9, https://doi.org/10.4401/ag-7564, 2017.

Wardle, C. S., Carter, T. J., Urquhart, G. G., Johnstone, A. D. F., Ziolkowski, A. M., Hampson, G., and Mackie, D.: Effects of seismic air guns on marine fish, Cont. Shelf Res., 21, 1005-1027, 2001.
Wilkinson, M. D., Dumontier, M., I. J., Aalbersberg, G., Appleton, M., Axton, A., Baak, N. Blomberg, J. W., Boiten, L. B. da Silba Santos, P. E. Bourne, J., Bouwman, A. J. Brookes, T. Clark, M. Crosas, I. Dillo, O. Dumon, S. Edmunds, C. T. Evelo, R. Finkers, A. Gonzalez-Beltran, A. J. G., Gray, P. Groth, C. Goble, J. S. Grethe, J. Heringa, P.A., C'tHoen, R. Hooft, T. Kuhn, R. Kok, K. Kok, S. L. Lusher, M. E. Martone, A. Mons, A. L. Packer, B., Persson, P. Rocca-Serra, M., Roos, R. van Schaik, S. A. Sansone, E. Schultes, T. Sengstag, T. Slater, G., Strawn, M. A., Swertz, M. Thompson, J. van der Lei, E. van Mulligen, J. Velterop, A. Waagmeesetr, P. Wittenburg, K. Wolstencroft, J. Zaho, and B. Mons.: The FAIR Guiding Principles for scientific data management and stewardship, Scientific Data, 3, 160018, https://doi.org/10.1038/sdata.2016.18, 2016.

Wilkinson, R. and Pickett, K.: The Spirit Level: Why Equality is Better for Everyone, J. Soc. Policy, 42, 840-842, https://doi.org/10.1017/S0047279413000366, 2010.

Wyss, M. and Peppoloni, S. (Eds.): Geoethics, Ethical Challenges and case studies in earth sciences, Amsterdam-OxfordWaltham, Elsevier, Hungarian geographical Bulletin, 65, 450 pp., https://doi.org/10.15201/hungeobull.65.3.10, 2015. 